\title{
Novel method for manufacturing of aerocellulose
}

\author{
D. M. Rein \& Y. Cohen \\ Technion - Israel Institute of Technology, \\ Department of Chemical Engineering, Haifa, Israel
}

\begin{abstract}
The suggested novel method for producing the aerocellulose allows the elimination of cellulose hydrogel collapse at oven drying, caused by capillary forces. The addition of a compatible reactive agent (trimethylchlorosilane) and its diffusion into the water-swollen cellulose hydrogel pores results in a reaction with water, forming a leaving compound (hydrochloric acid) and a remaining hydrophobic compound (hexamethyldisiloxane), which fills the initially hydrophilic cellulose hydrogel pores, replacing and removing the remaining water. The cellulose gel pores, filled by hexamethyldisiloxane, have a low intrinsic surface tension thus allowing minimal shrinkage during very cheap oven drying. All known processes for manufacturing the aerocellulose do not allow its production at a reasonable cost.
\end{abstract}

Keywords: cellulose, hydrogel drying, aerocellulose.

\section{Introduction}

Plastics manufacturing processes utilize about $7-8 \%$ of the global use of crude oil. However, as oil resources are depleted, it is logical to seek other sources of sustainable and renewable polymers. Cellulose is by far the most abundant polymer on earth, constituting around $70 \%$ of the total biomass; it is chemically stable, insoluble in common liquids and does not thermally degrade below about $200^{\circ} \mathrm{C}$ in air. Furthermore, cellulose readily biodegrades and integrates in a closed carbon life cycle.

Aerogels are a class of materials, which are characterised by their highly porous structure and their low solids content. They are obtained from wet gels by drying, largely maintaining the openness of the structure. If the structure 
collapses during drying, the resulting material is termed xerogel. Although often considered a recent high-tech product, the first aerogels were actually synthesised in the 1930s by Kistler [1]. A variety of aerogels were produced from various materials such as silica, alumina, rubber, polyurethane and even cellulose derivatives. During the last decade interest in this class of materials has re-emerged. Most commonly known are inorganic aerogels based on silica, which are already used in several applications. At the last years the producing the aerogels from cellulose (aerocellulose) received a large development.

In aerocellulose production processing there are two essential steps: the production of a suitable lyogel and subsequent replacement of solvent by air, i.e. drying. The drying step is complicated by the occurrence of capillary forces in the gel pores that make the gel shrink up to gluing of the pore walls. Shrinkage can be eliminated almost completely by the use of supercritical fluids for drying, freeze-drying or spray-drying [2-4], which could be applied to cellulose lyogels obtained, for example, from ionic liquid (IL) solutions.

Since the end of 1990s the usage of ILs as "green" non-derivatizing solvents for cellulose-based applications has quickly risen [5-7]. The most investigated ILs which are used for cellulose dissolution are 1-butyl-3-methylimidazolium chloride and 1-allyl-3-methylimidazolium chloride. As a result of their minuscule vapour pressure, ionic liquids minimize the atmospheric solvent loss, and associated flammability hazard. In the case of thermal decomposition, this process in ionic liquids is not autocatalytic or explosive, its toxicity is low. According to Hermanutz et al. [8], the novel solvent: 1-ethyl-3methylimidazolium acetate (EMIMAc), has a significant priority as compared to the aforementioned ionic liquids because it is liquid at room temperature and less toxic and corrosive than IL containing halogen anions. The cellulose concentration could be varied in a wide range, from dilute (about $0.1 \% \mathrm{wt}$.) to an almost concentrated state (more than $15 \% \mathrm{wt}$.), and the solution temperature could be changed from 0 to $140^{\circ} \mathrm{C}$.

\section{Experimental}

The suggested novel aerocellulose producing process consists of several stages.

\subsection{Preparation of cellulose solution}

The initial solution was prepared by dissolution of as-received cellulose microcrystalline powder (Aldrich) in EMIMAc (BASF) at the wide range of concentrations at temperatures of $20-90^{\circ} \mathrm{C}$ using a magnet stirrer.

\subsection{Preparation of cellulose hydrogel}

Cellulose in its ionic liquid solutions can be easily precipitated at room temperature by the addition of water, methanol, ethanol or acetone, forming, hydro-, alco-, acetono- and other cellulose lyogels, respectively (Swatloski et al. [9]). We prepared a hydrophilic cellulose hydrogel (hCell) by coagulating the cellulose solution in EMIMAc with deionized water $\left(25^{\circ} \mathrm{C}\right.$; about $30 \mathrm{ml}$ per 
$100 \mathrm{ml}$ of solution). To explore the scope for the processing of cellulose hydrogels from ILs, we prepared cellulose hydrogels from the initial cellulose solutions of the different concentrations from 0.2 to $8 \% \mathrm{wt}$.

The IL was recovered and reused after water vacuum evaporation.

\subsection{Method of hydrophobization of cellulose hydrogel}

After draining the excess water/IL mixture, an hydrophobic liquid hexamethyldisiloxane: $\left(\mathrm{CH}_{3}\right)_{3} \mathrm{Si}-\mathrm{O}-\mathrm{Si}\left(\mathrm{CH}_{3}\right)_{3}$ (HMDSO), is placed above the water-swollen hydrogel (Schwertfeger et al. [10]). The addition of a reactive agent - trimethylchlorosilane: $\left(\mathrm{CH}_{3}\right)_{3} \mathrm{SiCl}$ (TMCS) into the HDMO layer, its diffusion into the gel pores results in a reaction with water forming a leaving compound such as $\mathrm{HCl}$ and remaining compound, in this case again HDMO, which fills the cellulose hydrogel pores replacing and removing the remaining water and residual solvent. The reaction product of aqueous HCL is encouraged to leave the gel by virtue of its higher density as well as the higher specific volume of the reaction product HMDO filling the pores. Depending on the reaction conditions there are two possible reaction paths. At lower TMCS activity the cellulose is mostly unreacted and thus a hydrophilic cellulosic gel is imbibed with the hydrophobic liquid HMDO. At higher TMCS activity silation of the cellulosic pore surface can occur concurrently. Both may be desirable consequences.

In principle three different reactions can occur:

$$
2\left(\mathrm{CH}_{3}\right)_{3} \mathrm{SiCl}+\mathrm{H}_{2} \mathrm{O} \rightarrow\left(\mathrm{CH}_{3}\right)_{3} \mathrm{Si}-\mathrm{O}-\mathrm{Si}\left(\mathrm{CH}_{3}\right)_{3}+2 \mathrm{HCl}
$$

Reverse reaction between $\mathrm{HMDSO}$ and $\mathrm{HCl}$ :

$$
\left(\mathrm{CH}_{3}\right)_{3} \mathrm{Si}-\mathrm{O}-\mathrm{Si}\left(\mathrm{CH}_{3}\right)_{3}+2 \mathrm{HCl} \rightarrow 2\left(\mathrm{CH}_{3}\right)_{3} \mathrm{SiCl}+\mathrm{H}_{2} \mathrm{O}
$$

Reaction of silation (hydrophobization) of cellulose gel surface:

$$
\mathrm{TMCS}+\mathrm{hCell}-\mathrm{OH} \leftrightarrows \mathrm{hCell}-\mathrm{O}-\mathrm{Si}\left(\mathrm{CH}_{3}\right)_{3}+\mathrm{HCl}
$$

TMCS reacts with the pore water to yield HMDSO and $\mathrm{HCl}$ in a spontaneous and exothermic reaction (eqn (1)). HMDSO can again react with $\mathrm{HCl}$ to form TMCS and water (eqn (2)). The equilibrium of these reactions is clearly on the HMDSO synthesis side, because of the fact that all $\mathrm{HCl}$, coming from the reaction, instantly dissolves in the surrounding water, so as to leave the reaction zone jointly with the displaced pore water. The not reacted pore water is pressed out of the gel, since the synthesized HDMSO has a far larger molar volume than water and is not miscible with it. Removing $\mathrm{HCl}$ and impregnation with immiscible with it HDMSO also sufficiently decreases the acidic degradation of cellulose. In the third possible reaction TMCS reacts with the hydroxyl groups on the surface of the cellulose gel (eqn (3)), stimulating its hydrophobization. Simultaneously, the reverse reaction is possible - hydrolyze of silated cellulose 
by $\mathrm{HCl}$ acid. The equilibrium of this reaction is clearly on the silation side, because of $\mathrm{HCl}$ removing from the reaction zone together with the displaced pore water.

Different amounts of TMCS were added to the hydrogel/HMDSO suspension (0.01- $0.4 \mathrm{~mol} \mathrm{TMCS} / \mathrm{mol}$ of hCell) at different temperatures $\left(20-90^{\circ} \mathrm{C}\right)$, resulting in domination of different reactions (eqns (1) or (3)). After reaction (which occurred within about $15 \mathrm{~min}$ ) the resulting liquids were drained and lyogel was rinsed in pure HDMSO for $30 \mathrm{~min}$.

\subsection{Drying of the cellulose lyogel}

The resulting cellulose lyogel was then applied to a plastic cap and dried. The drying process was realized in the vacuum oven at temperature $20-90^{\circ} \mathrm{C}$ for 12 -24 hours.

\section{Materials characterization}

The gel shrinkage after vacuum oven drying is shown in fig. 1. It is seen that shrinkage of the cellulose hydrogel sample was more than $75 \%$ at that time as the shrinkage of cellulose lyogel one, prepared according to the described method, was less than $20 \%$.

Fig. 2a-c shows scanning electron microscope (SEM) pictures of aerocellulose prepared according to the suggested method from solutions with different cellulose contents at $60^{\circ} \mathrm{C}$. Explicitly the network structure becomes finer and the pores getting smaller the lager the cellulose concentration is. The

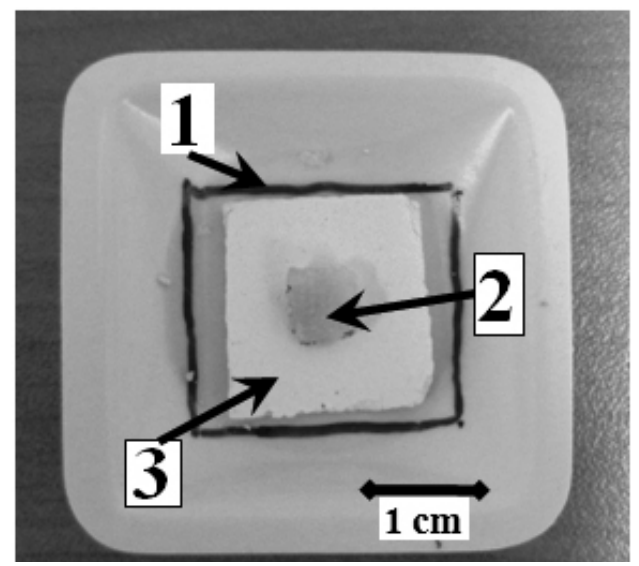

Figure 1: Cellulose samples after drawing: 1 - initial size of gel samples; 2 - dried cellulose hydrogel, 3 - dried lyogel, produced according to the suggested process. Initial cellulose solution in EMIMAc, $3 \% \mathrm{wt}$, was prepared at $60^{\circ} \mathrm{C}$. The sample drying was realized in a vacuum oven at room temperature for 18 hours. 


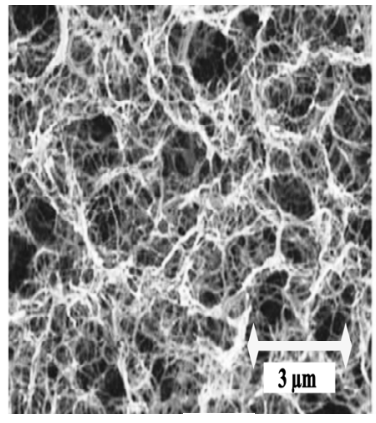

a

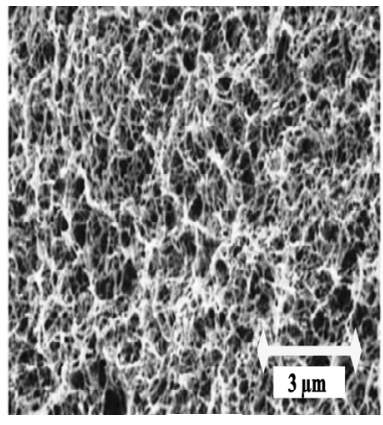

b

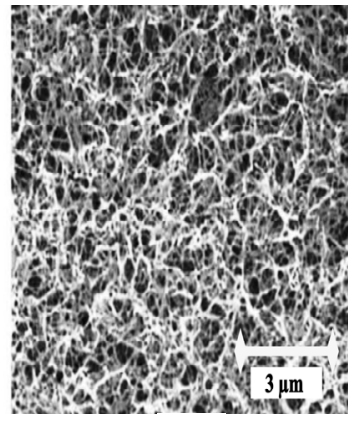

c

Figure 2: $\quad$ SEM photoes of cellulose aerogel prepared from solutions of different concentrations: $\mathrm{a}-0.5 \% \mathrm{wt}$., $\mathrm{b}-2 \% \mathrm{wt}$., $\mathrm{c}-6 \% \mathrm{wt}$.

pores visible in these pictures have sizes ranging from about 0.3 to $2 \mu \mathrm{m}$. The pore size spectrum seems to become more regular with increasing cellulose content.

\section{Conclusion}

The advantages of our novel method consist of the possibility to produce commercially viable aerocellulose that; will use low-cost "green" precursors such as cellulose, water and minimum of "green", easy recyclable ionic liquid solvent; does not require expensive high-pressure supercritical or freeze drying; shortens the process times at each step and adaptation upon existing unit operations and equipment.

We have realized the direct path from a hydrogel to the silated lyogel that allows economic production of larger aerogel particles, avoiding an expensive solvent exchange process and subsequent distillation as is in the traditional processes. The displaced by-products: hydrophobic HDMSO, water and $\mathrm{HCl}$, dissolved in it, are naturally phase separated and could be easily reused (HDMSO) in the same process. In addition, no slow, diffusion controlled solvent exchange is necessary for the waste recycling process, which sufficiently reduces its cost.

\section{References}

[1] Kistler, S. S., Method of producing aerogels. U.S. Patent 2,093,454, 1937.

[2] Pierre, A. C. \& Pajonk, G. M., Chemistry of aerogels and their applications. Chemical Review, 102, pp. 4243-4265, 2002.

[3] Khare V. P., Greenberg A. R., Kelley S. S., Pilath H., Roh I. J. \& Tyber J., Synthesis and characterization of dense and porous cellulose film. Journal of Applied Polymer Science, 105, pp. 1228-1236, 2007. 
68 High Performance Structures and Materials V

[4] Duchemin B. J.C., Staiger M. P., Tucker N. \& Newman R. H., Aerocellulose Based on All-Cellulose Composites, Journal of Applied Polymer Science, 115, pp. 216-221, 2010.

[5] Tsioptsias C., Stefopoulos A., Kokkinomalis I., Papadopoulou L. \& Panayiotou C., Development of micro- and nano-porous composite materials by processing cellulose with ionic liquids and supercritical $\mathrm{CO}_{2}$, Green Chemistry, 10, pp. 965-971, 2008.

[6] Li L., Lin Z., Yang X., Wan Z. \& Cui Sh., A novel cellulose hydrogel prepared from its ionic liquid solution, Chinese Science Bulletin, 54, pp. 1622-1625, 2009.

[7] Aaltonen O. \& Jauhiainen O., The preparation of lignocellulosic aerogels from ionic liquid solutions, Carbohydrate Polymers, 75, pp. 125-129, 2009.

[8] Hermanutz F., Gahr F., Uerdingen E., Meister F. \& Kosan B., New Developments in Dissolving and Processing of Cellulose in Ionic Liquids, Macromolecular Symposia, 262, pp. 23-27, 2008.

[9] Swatloski R. P., Spear S. K., Holbrey J. D. \& Rogers R. D., Dissolution of Cellulose with Ionic Liquids, Journal of American Chemical Society, 124, pp. 4974-4975, 2002.

[10] Schwertfeger F, Frank D. \& Schmidt M., Hydrophobic waterglass based aerogels without solvent exchange or supercritical drying, Journal of NonCrystalline Solids, 225, pp. 24-29, 1998. 